\title{
Risk factor assessment to anticipate performance in the National Developmental Screening Test in children from a disadvantaged area
}

\author{
Alejandro Montes, M.D. ${ }^{a}$, and Gustavo Pazos, M.D. ${ }^{d, e}$ \\ Collaborators: Noelia Lesta, M.D. ${ }^{b}$, Virginia Álvarez, B.S. ${ }^{c}$, and Mariel Aranda, B.S.c
}

a. Department of Pediatrics.

b. General Medicine Residency Program.

c. Social Services. Hospital Provincial "Dr. Andrés Isola".

d. Universidad Nacional de la Patagonia San Juan Bosco (UNPSJB).

e. Centro Nacional Patagónico (CONICETCENPAT).

E-mail Address:

Alejandro Montes, M.D.: alejandroenriquemontes @gmail.com

Funding:

A large body of data used in this research work were obtained from the research project titled "Screening for child developmental disorders in a socioeconomically disadvantaged population from Puerto Madryn, Chubut. An opportunistic or a standardized approach?" funded through a "Ramón Carrillo-Arturo Oñativia Scholarship", granted by the Health Research Committee (Comisión Nacional Salud Investiga) and the National Ministry of Health, at the Health Service, initiation category (scholarship holder: Noelia Lesta, M.D.; scholarship director: Alejandro Montes, M.D.; institution: Hospital Andrés Isola; year: 2008).

Conflict of interest: None.

Received: 11-9-2014 Accepted: 7-15-2015

\begin{abstract}
Introduction. Identifying children at risk of failing the National Developmental Screening Test by combining prevalences of children suspected of having inapparent developmental disorders (IDDs) and associated risk factors (RFs) would allow to save resources.

Objectives.1.Toestimatetheprevalence of children suspected of having IDDs. 2. To identify associated RFs. 3. To assess three methods developed based on observed RFs and propose a pre-screening procedure.

Materials and Methods. The National Developmental Screening Test was administered to 60 randomly selected children aged between 2 and 4 years old from a socioeconomically disadvantaged area from Puerto Madryn. Twenty-four biological and socioenvironmental outcome measures were assessed in order to identify potential RFs using bivariate and multivariate analyses. The likelihood of failing the screening test was estimated as follows: 1 . a multivariate logistic regression model was developed; 2. a relationship was established between the number of RFs present in each child and the percentage of children who failed the test; 3 . these two methods were combined.

Results. The prevalence of children suspected of having IDDs was $55.0 \%$ (95\% confidenceinterval: $42.4 \%-67.6 \%$ ). Six RFs were initially identified using the bivariate approach. Three of them (maternal education, number of health checkups and Z scores for height-for-age, and maternal age) were included in the logistic regression model, which has a greater explanatory power. The third method included in the assessment showed greater sensitivity and specificity $(85 \%$ and $79 \%$, respectively).

Conclusions. The estimated prevalence of children suspected of having IDDs was four times higher than the national standards. Seven RFs were identified. Combining the analysis of risk factor accumulation and a multivariate model provides a firm basis for developing a sensitive, specific and practical pre-screening procedure for socioeconomically disadvantaged areas.
\end{abstract}

Key words: screening, developmental disabilities, primary health care.

http:/ / dx.doi.org/10.5546/aap.2016.eng.44

\section{INTRODUCTION}

In 2002, the National Developmental Screening Test (Prueba Nacional de
Pesquisa del Desarrollo, PRUNAPE) was assessed and its ability to detect children younger than 6 years old suspected of having inapparent developmental disorders (IDDs) was verified. ${ }^{1}$ Previously, it had been demonstrated that exposure to different combinations of risk factors (RFs) increased the likelihood of having a developmental disorder. ${ }^{2,3}$ Reliable estimations of the prevalence of children suspected of having IDDs in specific groups of Argentine populations and lists of RFs associated to an increased likelihood of failing the screening test were obtained from those previous studies. ${ }^{4-7}$

Knowing in advance who would have a greater chance of failing the test and focusing the screening on these children, without inadequately disregarding sensitivity and specificity, might be important in socioeconomically disadvantaged areas so as to reduce the number of children to be assessed, and save time and other resources. However, we found only one regional article that combined different RFs to predict development among socioeconomically disadvantaged infants, ${ }^{8}$ and no article on the subsequent age group, which, concomitantly, reduces the number of contacts with the health system and has restricted access to early health care services.

In this study, different socioenvironmental and biological outcome measures were assessed, and the PRUNAPE ${ }^{9}$ was administered to a random sample of 2- to 4-yearold children in socioeconomical disadvantage from the city of Puerto Madryn, and who had no other 
conditions that may affect their development, except malnutrition. The study had three objectives: 1 . to estimate the prevalence of children suspected of having IDDs; 2 . to identify associated RFs that may be collected during a medical visit; and 3. to assess three methods developed based on observed RFs and propose a pre-screening procedure.

\section{MATERIAL AND METHODS}

\section{Population and sample selection}

Research was conducted between February $1^{\text {st }}$, 2009 and April 1', 2010 at the Pujol Programmatic Area (PPA), dependent on the "Dr. Favaloro" Health Care Center (HCC), which offers primary care services at the Puerto Madryn's Hospital, a city with approximately 69000 inhabitants at the time. $^{10}$

Around $65 \%$ of the inhabitants were owners of houses built by themselves and had basic services (region 1); the rest lived in slum areas (region 2). Twenty-four percent of all city inhabitants were of Quechua ethnicity and bilingual.

Among the approximately 8000 people living near the PPA, 199 children born in 2006 were identified based on birth certificates filed at the Office of Vital Records, medical records filed at the HCC and family records of community workers. These children were georeferenced and visited. In order not to include certain risk groups that are specifically surveyed and highlight a possible environmental effect on development, children with the following characteristics were excluded: 1. gestational age (GA) $<37$ weeks; 2 . birth weight $(B W)<2500$ grams; 3 . on mechanical ventilation; 4 . disease that overtly compromised development, except malnutrition; 5. length of stay longer than 30 days (at a hospital, childcare home and/or in prison); 6. arrival at the PPA after three months of life. Thus, the eligible population was as follows: 156 children living in the PPA, born in 2006 and with no overt developmental condition. To estimate the prevalence of children suspected of having IDDs with a desired accuracy level of $20 \%$, the sample size was estimated at 70 children, assuming a prevalence of $50 \%$, similar to that observed in comparable age and social status groups, ${ }^{1,2,4}$ and a non-response rate of $15 \%$. Therefore, a random sample stratified by region and proportional to the population size of each region was established, using the case numbering and number drawing method. Four families refused to participate; six participants were excluded for non-compliance with the protocol approved by the hospital's Ethics Committee. The definite sample consisted of 60 children, 39 from region 1 and 21 from region 2 . The sample ratio was 1:2.6. Participating families received information on the project before signing the informed consent.

\section{Prevalence of children suspected of having inapparent developmental disorders}

A pediatrician certified to administer the PRUNAPE assessed the 60 participants in accordance with the authors' recommendations. ${ }^{9}$ Children who failed the test were assessed and followed-up using local community resources (Annex 1). The prevalence of children suspected of having IDDs and the corresponding 95\% confidence interval (CI) were calculated.

\section{Risk factor assessment}

A general practitioner assessed children' nutritional status by means of an anthropometric measurement in accordance with the criteria established. ${ }^{11}$ Height and weight were recorded. Two indexes were developed: height-for-age and weight-for-height, expressed as the $\mathrm{Z}$ scores for the median reference population (World Health Organization [WHO], 2006). ${ }^{12}$

Two social workers visited parents at home and interviewed them to assess the household socioeconomic status based on the socioeconomic level (SEL) index ${ }^{13}$ (Annex 2) and recorded data to identify potential RFs using a customized questionnaire.

Twenty-seven outcome measures representative of different biological and socioenvironmental dimensions that may be collected at a HCC were pre-selected (Annex 2). These were defined and categorized based on a risk assessment theoretical model ${ }^{14}$ (level 0 : sex; level 1: related to social status; level 2: related to reproductive and socioenvironmental characteristics; level 3: related to birth; level 4: related to care provided to the child; level 5: related to malnutrition and other health problems). Three outcome measures were disregarded: family risk (low reliability), breastfeeding (inadequate questionnaire), and wasting (no cases) (Annex 2). Table 1 details the 24 included outcome measures, their hierarchical order and general values.

In order to identify RFs for children suspected of having IDDs, a bivariate analysis was done for each outcome measure comparing values between the group who passed the PRUNAPE 
and the group who failed it. Outcome measures with a significance level of $p \leq 0.05$ were accepted. For quantitative outcome measures, statistical significance was assessed by comparing the mean value of each group using Student's t test, once assumptions of normality and homogeneity of variances were verified. If such assumptions were not met, a non-parametric MannWhitney's test was performed. For categorical outcome measures, comparisons were made using a 2 test for contingency tables with Yates' correction.

\section{Assessment of methods to anticipate the likelihood of failing the National Developmental Screening Test}

The likelihood of failing the PRUNAPE was estimated using three methods: 1 . a multivariate logistic regression model was developed; 2 . a relationship was established between the number of RFs present in each child and the percentage of children who failed the test; 3 . these two methods were combined. For the first method, the outcome measure used was a dichotomous response to the PRUNAPE result: pass/fail, and outcome measures with a significance value of $p<0.10$ were included in the bivariate analysis as explanatory outcome measures (Table 1). In order to avoid multicollinearity, Spearman's correlation matrix was analyzed and only outcome measures with a coefficient $<0.5$ were assessed simultaneously in a model. Multivariate models with increasing complexity were developed using the Enter method and respecting the

TABLE 1. Mean values and proportions of assessed outcome measures among groups of children who passed or failed the National Developmental Screening Test

\begin{tabular}{|c|c|c|c|c|c|}
\hline Level & Outcome measure ${ }^{1,5}$ & $\begin{array}{l}\text { PRUNAPE } \\
\text { Passes }\end{array}$ & Fails & $p^{3}$ & Threshold $^{4}$ \\
\hline 0 & Proportion of boys & 0.52 & 0.52 & 1 & -- \\
\hline 1 & $\begin{array}{l}\text { Score at the SEL scale } \\
\text { Maternal education (in years)*\# } \\
\text { Educational environment (in years)* } \\
\text { Proportion of heads of household with an unstable job } \\
\text { Proportion of heads of household with a qualified job }\end{array}$ & $\begin{array}{c}22.96(0.91) \\
8.1(0.4) \\
7.7(0.4) \\
0.27 \\
0.50\end{array}$ & $\begin{array}{c}20.58(1.06) \\
6.6(0.4) \\
6.3(0.4) \\
0.42 \\
0.39\end{array}$ & $\begin{array}{l}0.29 \\
0.02 \\
0.05 \\
0.34 \\
0.58\end{array}$ & $\begin{array}{l}<8 \text { years old } \\
<8 \text { years old } \\
-- \\
--\end{array}$ \\
\hline 2 & $\begin{array}{l}\text { Children's age (in years) } \\
\text { Proportion of families of Quechua ethnicity } \\
\text { Proportion of separated parents } \\
\text { Maternal age (in years)\# } \\
\text { Number of children* } \\
\text { Proportion of pathological pregnancies }\end{array}$ & $\begin{array}{c}2.77(0.07) \\
0.15 \\
0.31 \\
22.9(1.0) \\
2.5(0.3) \\
0.08\end{array}$ & $\begin{array}{c}2.92(0.06) \\
0.30 \\
0.27 \\
26.2(1.3) \\
3.4(0.3) \\
0.22\end{array}$ & $\begin{array}{l}0.08 \\
0.27 \\
0.99 \\
0.08 \\
0.03 \\
0.26\end{array}$ & $\begin{array}{c}-- \\
-- \\
-- \\
\geq 24 \text { years old } \\
\geq 3 \text { children } \\
--\end{array}$ \\
\hline 3 & $\begin{array}{l}\text { Birth weight (in grams) } \\
\text { Proportion of infants with insufficient birth weight } \\
\text { Proportion of mothers who are full-time housewives } \\
\text { Proportion of mothers who work a lot outside the home }\end{array}$ & $\begin{array}{l}3432.6(81.3) \\
0.19 \\
0.63 \\
0.11\end{array}$ & $\begin{array}{c}3357.3(73.4) \\
0.15 \\
0.67 \\
0.06\end{array}$ & $\begin{array}{c}0.49 \\
1 \\
0.98 \\
0.81\end{array}$ & $\begin{array}{l}-- \\
-- \\
--\end{array}$ \\
\hline 4 & $\begin{array}{l}\text { Proportion of only children } \\
\text { Proportion of first-born children* } \\
\text { Proportion of informal childcare } \\
\text { Proportion of mixed childcare } \\
\text { Health checkups*\# } \\
Z \text { scores for } H-A^{* \#}\end{array}$ & $\begin{aligned} & 0.26 \\
& 0.58 \\
& 0.82 \\
& 0.19 \\
& 2.7(0.4) \\
&-0.274(0.241)\end{aligned}$ & $\begin{array}{c}0.15 \\
0.24 \\
0.75 \\
0.25 \\
1.9(0.3) \\
-0.859(0.184)\end{array}$ & $\begin{array}{l}0.48 \\
0.02 \\
0.78 \\
0.78 \\
0.04 \\
0.05\end{array}$ & $\begin{array}{c}-- \\
(4 \mathrm{a}) \\
-- \\
-- \\
(4 b) \\
\leq 0.50 \mathrm{SD}\end{array}$ \\
\hline 5 & $\begin{array}{l}\text { Proportion of obese patients }{ }^{2} \\
\text { Proportion of children with significant diseases }\end{array}$ & $\begin{array}{l}0.12 \\
0.46\end{array}$ & $\begin{array}{l}0.09 \\
0.42\end{array}$ & $\begin{array}{l}0.36 \\
0.98\end{array}$ & -- \\
\hline
\end{tabular}

PRUNAPE: National Developmental Screening Test; SEL: socioeconomic level; H-A: height-for-age; SD: standard deviation.

\footnotetext{
${ }^{1}$ Outcome measures selected as risk factors are indicated in italics.

* Outcome measures selected based on the bivariate analysis.

\# Outcome measures selected according to the multivariate logistic regression model (Table 2).

${ }^{2} \mathrm{~W}-\mathrm{H}>+2 \mathrm{SD}$ as per the WHO references.

${ }^{3} \mathrm{P}$ value indicates the significance of the group comparison.

${ }^{4}$ Definition used as threshold for outcome measures selected as risk factors.

4a Not a first child.

${ }^{4 b}$ Two or less checkups in children younger than 2 years old and one checkup in children younger than 3 years old.

${ }^{5}$ For continuous outcome measures, the standard error is indicated in parentheses.
} 
hierarchical order. The models' goodness of fit and explanatory power were assessed using Hosmer-Lemeshow test, Cox-Snell $\mathrm{R}^{2}$, the table of classification of correctly and incorrectly predicted cases, and the area under the receiving operator characteristics (ROC) curve. The model with more explanatory power was selected.

For the second method, children were categorized based on the number of RFs identified in the bivariate and multivariate analyses and relating the number of RFs to the percentage of cases who failed the PRUNAPE in each category. For each RF, threshold values were defined and used to establish which children were exposed to RFs (Table 1). For the third model, a relationship was established between the likelihood of failing the PRUNAPE as per the multivariate model and the number of RFs. Statistical analyses were conducted using the R 2.13.0. ${ }^{15}$ software.

\section{RESULTS}

Population, sample and prevalence of children suspected of having inapparent developmental disorders

The sample was an adequate representation of the distribution of the eligible population (Annex 3 ). The prevalence of children suspected of having IDDs was $55.0 \%$, and $95 \%$ confidence interval limits were $42.4 \%$ and $67.6 \%$.

\section{Risk factors for children suspected of having inapparent developmental disorders}

The bivariate analysis identified six RFs for children suspected of having IDDs distributed among four of the six hierarchies. A low level of maternal education, combined parental education level, having other siblings or a low height-forage (H-A) ratio were associated with a higher risk of failing the PRUNAPE. Being a first child and having more health checkups in the previous year are related to a higher likelihood of passing the test (Table 1).

\section{Assessment of methods to anticipate the likelihood of failing the National Developmental Screening Test}

Method 1. The logistic regression model with more explanatory power for children suspected of having IDDs included four outcome measures (no constant term): maternal education, number of health checkups and $Z$ scores for height-for-age, which were negatively associated to the result, and maternal age, which showed a positive association (Table 2). Thus, the equation to estimate the likelihood of failing the PRUNAPE for a particular case is shown in Table 3.

Cases of L-children suspected of having IDDs above 0.5 became candidates to participate in the screening, since this was the likelihood value that maximized the area under the ROC curve and, as a result, the explanatory power of sensitivity and specificity of $78.8 \%$ and $79.2 \%$, respectively.

Method 2. The percentage of children who failed the PRUNAPE increased with the amount of exposure to RFs until significantly exceeding the estimated population prevalence $(55.0 \%)$ once three or more of the RFs identified in both the bivariate and multivariate analyses were

TABLE 2. Coefficients among risk factors selected using the multivariate logistic regression model to explain the risk of failing the National Developmental Screening Test

\begin{tabular}{|c|c|c|c|c|}
\hline Outcome measure & Coefficient & Degree of freedom & $p$ & Odds ratio $(95 \% \mathrm{CI})^{*}$ \\
\hline Maternal education & $-0.205 \pm 0.110$ & 1 & 0.064 & $0.815(0.657-1.012)$ \\
\hline Maternal age & $0.117 \pm 0.041$ & 1 & 0.005 & $1.124(1.037-1.218)$ \\
\hline Health checkups & $-0.615 \pm 0.219$ & 1 & 0.005 & $0.541(0.352-0.830)$ \\
\hline Height-for-age & $-0.752 \pm 0.323$ & 1 & 0.020 & $0.472(0.250-0.889)$ \\
\hline
\end{tabular}

* Outcome measures were not categorized for analysis, therefore the odds ratio value indicates a change in the percentage of risk for failure at the PRUNAPE and the unit increase in the corresponding risk factor value.

TABLE 3. Equation to estimate the likelihood of failing the National Developmental Screening Test

$L$-children suspected of having IDDs $=\frac{1}{1+e^{(-0,205 \times I M+0,117 \times E M-0,615 \times N C s-0,752 \times \mathrm{TE})}}$

L: likelihood. ME: maternal education. MA: maternal age. NC: number of checkups. HA: Z score for height-for-age. 
accumulated (Z-test for proportions: $p=0.019$ and $p<0.001$, respectively) (Figure 2 ). When candidates for screening included children exposed to three

FIGURE 1. ROC curve for the multivariate logistic regression model

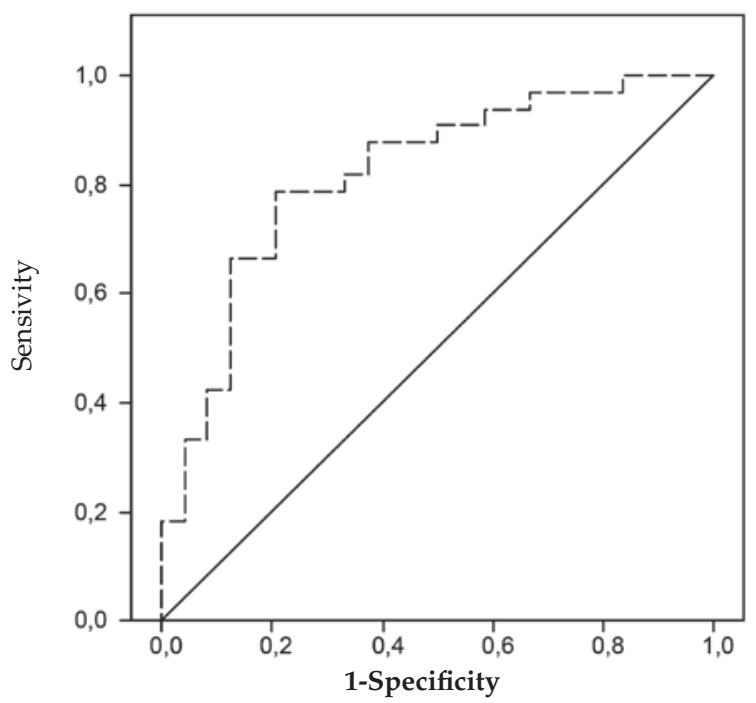

The area under the dotted line $(0.82 \pm 0.06)$ is significantly larger than 0.5 (solid line), which indicates a good to very good explanatory power $(\mathrm{P}<0.001)$.

FIGURE 2. Risk factor accumulation effect on the likelihood of failing the National Developmental Screening Test

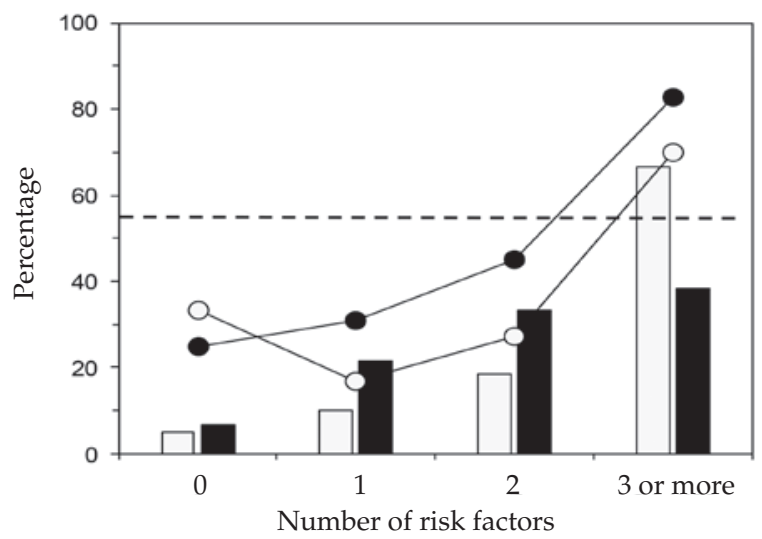

Bars indicate the percentage of children in the sample exposed to a different number of risk factors (RFs). Circles joined by lines, for each RF category $(0,1,2$ and 3 or more), indicate the percentage of children who failed the PRUNAPE. White indicates the bivariate approach (six RFs); black, the multivariate approach (four RFs). The dotted line indicates the prevalence of children suspected of having IDDs in the studied sample (55.0\%). or more RFs, the sensitivity of this procedure was approximately $85 \%$, and its specificity was $56 \%$ in the bivariate approach, and $58 \%$ and $85 \%$, respectively, in the multivariate approach.

Method 3. The previous two methods were combined so as to improve both the sensitivity and specificity to select candidates for screening. To this end, a relationship was established between the likelihood of failing the PRUNAPE as per the equation L-children suspected of having IDDs and the number of RFs (Figure 3). Such relationship resulted positive and significant (Pearson's correlation coefficient, $\mathrm{r}=0.73, p<0.001)$. By using the screening of all cases with three or more RFs as initial selection criteria and then using the equation L-children suspected of having IDDs for the remaining risk categories (except non-exposure), the sensitivity and specificity reached $85 \%$ and $79 \%$, respectively.

\section{DISCUSSION}

Prevalence of children suspected of having inapparent developmental disorders. More than half of children aged between 2 and 4 years old, with easy access to conventional health services and no overt developmental disorder

FIGURE 3. Likelihood of failing the National Developmental Screening Test based on the number of risk factors

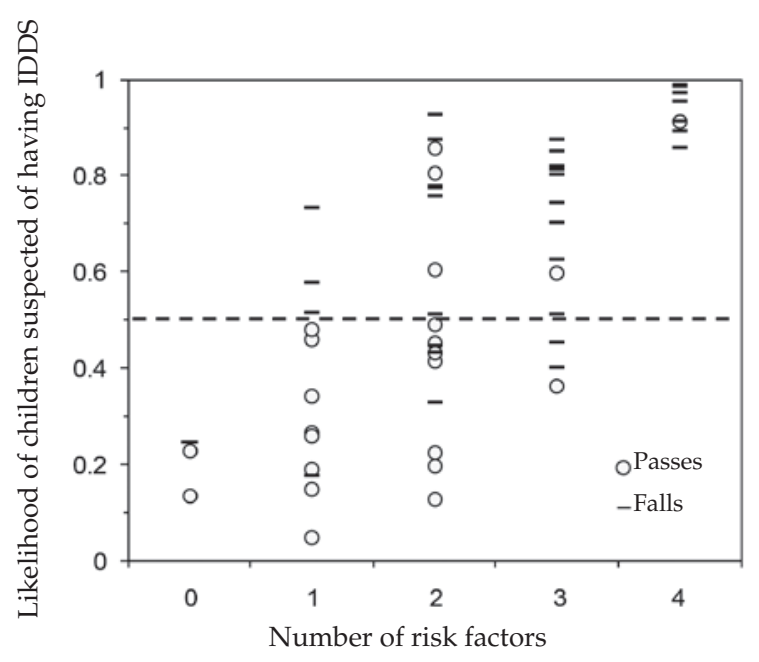

IDD: inapparent developmental disorders.

This figure shows the likelihood of failing the PRUNAPE as predicted by the multivariate logistic regression model based on the number of RFs to which each child was exposed. The dotted line indicates the cut-off value (0.5) above which cases are predicted to "fail" the test according to the model. Circles and dashes indicate children who passed and failed the PRUNAPE, respectively. 
or condition that may affect development failed the PRUNAPE. Such finding, similar to what has been observed in other socioeconomically disadvantaged populations of a comparable age from Argentina, ${ }^{4,6}$ is the result of a greater exposure to risks, especially psychosocial risks, which influence psychomotor development and alter brain functions that may be suspected through screening. ${ }^{2,16}$ Undoubtedly, it is imperative to generate multimodal interventions aimed at the populations and individuals at a higher risk to prevent and/or reverse them..$^{22,30-32}$

Risk factors for children suspected of having inapparent developmental disorders. The exploration of outcome measures that anticipated the likelihood of failing the test was supported on the above mentioned paradigm. Candidate outcome measures were selected based on their admissible influence on development given that they were easily collected at the doctor's office or due to their repetitive identification as RF in other investigations. ${ }^{4,7,16-21}$ Certain intermediate characteristics with more explanatory power, such as the ones that describe parenting abilities, were omitted because measuring them would require too much time, complex tools and trained personnel, all of which are rare at health care centers in disadvantaged areas. ${ }^{13,22}$

In addition to socioeconomic status, a major RF that has been widely described in the bibliography, ${ }^{6,7,17-21}$ other RFs are related to psychomotor development and, consequently, the test result, although the meaning and intensity of their influence may vary.

This investigation, as many other similar studies, verified an important reverse association between failing the test and parental education level, which was even stronger when considering only maternal education. ${ }^{4,6,7,23,24}$ Remarkably, all children whose mothers had completed less than six years of formal education failed the test. On the contrary, a low height-for-age had a direct effect on the test result. Previous studies, controlled for socioeconomic outcome measures, had already reported on the harmful effect of malnutrition on developmental level or intelligence quotient (IQ). ${ }^{25,29}$ The reverse effect on the outcome of higher number of health checkups in the previous year, which had not been previously reported, probably reflects a favorable upbringing, not a more qualified professional care.

In accordance with most publications, birth order was reversely associated with the likelihood of passing the PRUNAPE: first children had better chances than those born in the third place or later. . $^{, 13,25-27}$

Excluding the group of "teen mothers" who were younger than 16 years old at the time of giving birth and whose children failed the test, it could be said that, in general, an older maternal age had a direct effect on results, probably reflecting the limitations of time devoted to upbringing and/or fatigue with the maternal role. Both tendencies have been reported several times. ${ }^{727,28}$ Maternal age was identified as a RF only in the multivariate approach due to characteristics specific to the logistic regression model and its less restrictive condition, in statistical terms, to incorporate possible explanatory outcome measures (a value of $p<0.10$ was used).

Unlike what has been repetitively reported, , 4,6,7,17-21,26 a significant association between socioeconomic status (measured as per SEL), children sex or age and the risk of failing the test was not verified, probably due to the sample's homogeneity, the small age range and the relative small sample size, respectively.

Assessment of methods to anticipate the likelihood of failing the National Developmental Screening Test. The multivariate method (method 1), which did not include highly inter-correlated outcome measures, showed a sensitivity and specificity close to $80 \%$ to detect cases with a higher likelihood of failing the test; therefore, this became a provisional prescreening procedure. De Andraca, et al. ${ }^{8}$ predicted the risk of having developmental disorders and estimated the percentage of children affected as per the number of RFs. Method 2 was used in an analogous manner, using RFs selected in the bivariate and multivariate approaches, successively. As per the findings, only between $3 \%$ and $5 \%$ of children were not exposed to RFs, more than $75 \%$ had two or more RFs at the same time, and the percentage of children who failed the PRUNAPE, in both explorations, was over $70 \%$ in the higher risk categories (Figure 2). Thus, children with three or more RFs were considered "screenable" $(67 \%$ and $38 \%$ of the sample, having used the bivariate or multivariate analysis, respectively) because they exceeded the observed average number of children suspected of having IDDs (55\%). Although this procedure provided a quantitatively clear framework, it has a disadvantage: it requires a definite threshold value. Based on the RFs selected in the bivariate approach, sensitivity was high (85\%) but specificity was low (56\%); however, based 
on the RFs selected in the multivariate approach, sensitivity was restricted (58\%) and specificity was adequate $(85 \%)$.

When the combined method (method 3 ) was used, which implied screening children exposed to three or four RFs selected in the multivariate approach and those with a lower level of exposure, when the likelihood of children suspected of having IDDs was estimated to be equal to or higher than 0.5 , sensitivity improved (close to $85 \%$ ) and specificity remained adequate (79\%); therefore, this was the most effective case selection procedure and the most efficient method in terms of effort and time involved. Thus, if such procedure had been used in advance of administering the PRUNAPE to the studied population, the number of tests would have been reduced by $40 \%$ and an adequate detection capability would have been maintained because it would have allowed to identify $85 \%$ of children who failed the test.

The equation L-children suspected of having IDDs is relatively complex and should be used in children with one or two RFs, not included in high risk groups, either assessed or not in this study, and these should be the only ones to take the test. ${ }^{33}$ A spreadsheet in a computer or mobile phone may facilitate its implementation.

The sample size was restrictive so as to leave aside independent cases and validate methods. However, results provide a sound basis for other investigations to test them in socioeconomically disadvantaged regions, where administering developmental screening tests is time consuming ${ }^{6,34}$ and where self-administered screening tests have an inadequate sensitivity. ${ }^{35}$

\section{CONCLUSIONS}

The estimated prevalence of children suspected of having IDDs was four times higher than the national standards. ${ }^{1}$ Seven RFs associated to outcome were identified using bivariate and multivariate approaches. Only one RF (number of health checkups) was not reported. Combining the analysis of risk factor accumulation and a multivariate model provides a firm basis for developing a sensitive, specific and practical pre-screening procedure for socioeconomically disadvantaged areas.

\section{Acknowledgments}

We would like to thank community health workers Marta Ritchard, Laura Estigarribia and Gladys Oñate, who performed the georeferencing tasks for the eligible population, conducted initial visits and distributed general information on the project's main characteristics.

Also, to the staff of Kindergarten No. 464 and Nursery "Dr. Abrany" from Pujol neighborhood, especially to the authorities Sandra Bouveé and Verónica Maldonado, who provided their help and a friendly environment to administer the PRUNAPE to all participants included in the investigation.

\section{REFERENCES}

1. Pascucci MC, Lejarraga H, Kelmansky D, Álvarez M, et al. Validación de la Prueba Nacional de Pesquisa de trastornos de desarrollo psicomotor en niños menores de 6 años. Arch Argent Pediatr 2002;100(5):374-85.

2. Sameroff AJ, Seifer R, Barocas R, Zax M, Greenspan S. IntelligenceQuotientScores of 4-Year-Old Children:SocialEnvironmental Risk Factors. Pediatrics 1987;79(3):343-50.

3. King EH, Logsdon DA, Schroeder SR. Risk factors for developmental delay among infants and toddlers. Child Health Care 1992;21(1):39-52.

4. Lejarraga H. Menéndez AM, Menzano E, Guerra L, et al. PRUNAPE: pesquisa de trastornos del desarrollo en el primer nivel de atención. Arch Argent Pediatr 2008;106(2):119-25.

5. Lejarraga H, Berardi C, Ortale S, Contreras MM, et al. Crecimiento, desarrollo, integración social y prácticas de crianza en niños que viven con sus madres en prisión. Arch Argent Pediatr 2011;109(6):485-91.

6. Lejarraga H, Pascucci MC, Masautis A, Kelmansky D, et al. Desarrollo psicomotor infantil en la cuenca MatanzaRiachuelo: pesquisa de problemas inaparentes del desarrollo. Rev Argent Salud Pública 2014;5(19):17-24.

7. Lejarraga H, Pascucci MC, Krupitzky S, Kelmansky D, el al. Psychomotor development in Argentinian children aged 0 - 5 years. Paediatr Perinat Epidemiol 2002;16(1):47-60.

8. De Andraca I, Pino P, De La Parra A, Rivera F, Castillo M. Factores de riesgo para el desarrollo psicomotor en lactantes nacidos en óptimas condiciones biológicas. Rev Saúde Pública 1998;32(2):38-47.

9. Lejarraga H, Kelmansky D, Pascucci MC, Salamanco G. Prueba Nacional de Pesquisa PRUNAPE. Buenos Aires: Ediciones Fundación Hospital Garrahan; 2005.

10. Estimaciones de población total por departamento y año calendario Período 2001-2010. Serie análisis demográfico 34. Ministerio de Economía y Producción. Secretaría de Política Económica. Instituto Nacional de Estadística y Censos. [Accessed on: July 21, 2015]. Available at: www. indec.mecon.ar/nuevaweb / cuadros/2/estimacionesserie34.pdf.

11. Lejarraga H, Heinrich J, Rodríguez A. Normas y técnicas de mediciones antropométricas. Rev Hosp Niños BAires 1975;17:166-71.

12. World Health Organization. WHO child growth standards. Length/height-for-age, weight-for-age, weight-for-length, weight-for-height and body mass index-for-age: methods and development. Geneva, 2006. [Accessed on: January 13, 2011]. Available at: http://www.who.int/childgrowth/ standards/technical_report/en/.

13. Carmuega E, O Donnell A, Pollit E, Durán PT, et al. Proyecto Tierra del Fuego: Encuesta de Desarrollo Infantil. Buenos Aires: CESNI/Fundación Macri; 1996.

14. Victora CG, Huttly S, Fuchs SC, Olinto MT. The role of conceptual frameworks in epidemiological analysis: a 
hierarchical approach. Int J Epidemiol 1997;26(1):224-7.

15. The $\mathrm{R}$ Project for Statistical Computing: $\mathrm{R}$ Development Core Team. R: A Language and Environment for Statistical Computing. Vienna: The R Foundation, 2011. [Accessed on: July 22, 2015]. Available at: www.r-project.org.

16. Walker SP, Wachs TD, Gardner JM, Lozoff B, et al. Child development: risk factors for adverse outcomes in developing countries. Lancet 2007;369(9556):145-57.

17. Lira MI. Factores de riesgo para el desarrollo psicomotor del lactante de nivel socioeconómico bajo. Rev Chil Pediatr 1994;65(1):21-7.

18. Torralva T, Cugnasco I, Manso M, Sauton F, et al. Desarrollo mental y motor en los primeros años de vida: su relación con la estimulación ambiental y el nivel socio-económico. Arch Argent Pediatr 1999;97(5):306-16.

19. Halpern R, Giugliani ER, Victora CG, Barros FC, Horta BL. Fatores de risco para suspeita do atrasono desenvolvimento neuropsicomotor aos 12 meses de vida. Rev Chil Pediatr 2002;73(5):529-39.

20. Schonhaut L, Rojas P, Kaempffer AM. Factores de riesgo asociados a déficit del desarrollo psicomotor en preescolares denivel socioeconómico bajo. Comuna urbano rural, Región Metropolitana, 2003. Rev Chil Pediatr 2005;76(6):589-98.

21. WalkerSP, Wachs TD, Grantham-McGregorS, BlackMM, et al. Inequality in early childhood: risk and protective factors for early child development. Lancet 2011;378(9799):1325-38.

22. Torralva T, Cugnasco I. Estudios epidemiológicos sobre desarrollo infantil. In: O`Donnell A, Carmuega E. Hoy y mañana. Salud y calidad de vida de la niñez argentina. Villa La Angostura: CESNI; 1998.Págs.251-70.

23. Bryant GM, Davies KJ, Newcombe RG. The Denver Development Screening test. Achievement of test items in the first year of life by Denver and Cardiff infants. Dev Med Child Neurol 1974;16(4):474-84.

24. Porfiri H, Spotti M, Petriz G, Lejarraga H, et al. Effect of age, socioeconomic level, maternal education and paternal occupation on intellectual quotient of a representative sample of 900 children aged 4-12 years. J Pediatr 1976;89:326.

25. Bryant GM, Davies KJ, Newcombe RG. Standardization of the Denver Developmental Screening test for Cardiff children. Dev Med Child Neurol 1979;21(3):353-64.

26. Wu YT, Tsou KI, Hsu CH, Fang LJ, et al. Brief report: Taiwanese infants' mental and motor development--6-24 months. J Pediatr Psychol 2008;33(1):102-8.

27. Alvik A. Variables predicting low infant developmental scores: maternal age above 30 years is a main predictor. Scand J Public Health 2014;42(2):113-9.

28. Ozkan M, Senel S, Arslan EA, Karacan CD. The socioeconomic and biological risk factors for developmental delay in early childhood. Eur J Pediatr 2012;171(12):181521.

29. Grantham-McGregor SM, Walker SP, Chang S, Powell C. Effects of early childhood supplementation with and without stimulation on later development in stunted Jamaican children. Am J Clin Nutr 1997;66(2):247-53.

30. Lejarraga H, Pascucci C. Desarrollo psicomotor del niño. Consideraciones generales y necesidades actuales en la Argentina. In: O`Donnell A, Carmuega E. Hoy y mañana. Salud y calidad de vida de la niñez argentina. Villa La Angostura: CESNI;1998:223-50.

31. Hohl M, Carmuega E, Baez M, Albani M, et al. Proyecto Lobería. Una experiencia comunitaria para favorecer el desarrollo integral de los niños de 0 a 3 años. (1999-2002). Buenos Aires: CESNI; 2003.

32. Glascoe FP, Trimm F. Brief approaches to developmentalbehavioral promotion in primary care: updates on methods and technology. Pediatrics 2014;133(5):884-97.

33. Boggiano E, Breitman F, Andrade M. Manual para la Supervisión de la Salud de niños, niñas y adolescentes. Comité Nacional de Pediatría General Ambulatoria. Buenos Aires: FUNDASAP; 2010

34. Salamanco G, D Anna, Lejarraga H. Tiempo requerido para la administración de una prueba de pesquisa de trastornos del desarrollo psicomotor infantil. Arch Argent Pediatr 2004;102(3):165-69.

35. Lejarraga H, Kelmansky D, Lejarraga C, Charrúa G, et al. Validación de un formulario para la detección de niños con alto riesgo de padecer trastornos del desarrollo. Cuestionario PRUNAPE pre-pesquisa. Arch Argent Pediatr 2013;111(6):476-83. 


\section{Annex 1. \\ Assessment and follow-up of children with potential developmental delay in primary care settings}

\section{INTRODUCTION}

Children with likely developmental disorders recognized by any screening instrument at the primary care level require a comprehensive assessment, an adequate follow-up and, eventually, general interventions and/or more specific treatments. Some experts propose that a number of the different activities required to meet such goals, either partially or fully, should be done before proposing a referral and suggest that their number and complexity should be defined at a local level after studying the workplace and available resources. ${ }^{1,2}$

We will also explain the approach adopted to care for 33 children living in the area of responsibility of the Primary Health Care Center (PHCC) who, during their participation in a study titled "Risk factor assessment to anticipate performance in the National Developmental Screening Test in children from a disadvantaged area", failed the test. Here we will describe how available resources were organized and implemented, what actions were taken and how, the assessment, follow-up and re-assessment procedures, the number of children included and the proportion of dropouts, but without going into detail on the different hurdles related to inter-jurisdictions, budget, care and/or administration, among others, that were overcome in practice and that should also be foreseen.

\section{Initial coordination}

Before starting the investigation, three groups were set up by consensus of the Hospital's Board, the Primary Care Supervising Body and municipal and provincial coordinators from the Social Welfare Secretariats: a workforce made up especially by interested members of the PHCC (a pediatrician, a psychologist, a speech therapist, a physical therapist, two social workers, a nutritionist, and two community health workers), a panel of consultant physicians (an ophthalmologist and an educational psychologist, who were already working in the public subsector, and a pediatric neurologist, a pediatric psychiatrist, a speech and language therapist, and an audiologist, who were working only in the private and / or social welfare subsectors), and a panel made up of the authorities and coordinators of certain local institutions (two Child Development Centers [CDC], a provincial kindergarten [KG], a municipal nursery $[\mathrm{N}]$ and the "First Years" program [FYP]). Among other things, the following was agreed upon: 1. each children who failed the PRUNAPE would be initially examined at the PHCC by the pediatrician, the psychologist and the speech therapist; 2 . consultant physicians would keep a fluid communication with these healthcare providers, but would only do tests if all three of them signed a written referral, so as to make a rational use of resources; 3 . CDCs, KGs, Ns and the FYP would prioritize, according to their possibilities, admission of these children and help with recommendations provided by the PHCC members and consultant physicians.

\section{First assessment}

All children who failed the test were given an appointment to attend the PHCC and have separate interviews with the pediatrician, the psychologist and the speech therapist. Twenty-eight (28/33) children already had a medical record filed at the PHCC, but a previous concern on their psychomotor development had been recorded only in two.

As per their parents' request, seven children kept seeing their family physicians at the social welfare subsector; these physicians were informed of the test result and the existence of the consultant physician panel. Once social workers verified contact between primary care physicians and these participants' trustworthy provider, formal follow-up of this subgroup was deemed completed. Thanks to informal contact with these providers, sometimes perceived as interference but facilitated by the limited number of physicians and proximity, it was established that two of these children had been referred to a psychologist and to an educational psychologist, respectively, but none of the seven patients had received a specific diagnosis. 
The remaining 26 children attended their first visit, almost always accompanied by their mothers, and thus their assessment was started. At the end of the study, 23 children had completed their three initial visits; the other three had yet to complete their interview with the psychologist. Although families lived less than ten blocks away from the PHCC, a significant number of them required repeated visits to their home from the social workers and health community workers to complete interviews, which delayed follow-up initiation.

Once the child completed the first three visits, or earlier if the situation called for it, the three primary care providers met to establish whether the child had a developmental disorder based on their judgment and on a comprehensive developmental semiotics analysis. If they established this was the case, they tried to determine its extent (number of affected areas), its severity or complexity and, if possible, its nature. Then, they decided on the goals to meet and coordinated the report made to parents (almost always, the mother).

As per the interim criteria of the three PHCC providers, fifteen children $(15 / 23)$ had an "overall developmental delay" (more than one area involved); three $(3 / 23)$ had "relational disorders"; and eight $(8 / 23)$ had a "language developmental delay". A boy with "overall developmental delay" who also had "abnormal gait", and another boy who had a probable "language disorder" were referred to secondary care. The first boy was diagnosed with left hemiparesis of likely perinatal origin (an MRI scan was done); the second boy was diagnosed with specific language impairment (SLI) (he was referred to the neurology and psychology services and had a brainstem auditory evoked potentials [BAEPs] test done). The third boy considered to have significant "overall developmental delay" was also referred to the consultant physicians, who requested a genetic test, but the participant did not complete this step. A mother who had an apparent mood disorder was referred to the hospital's Mental Health Service, where she was diagnosed with depression by a psychiatrist; she was started on drug and psychological therapy. In addition, an adult alcohol abuser and a situation of family violence were identified. Two of the children related to these three cases had been categorized as having an "overall developmental delay", the third, as having an "overall developmental delay" and "relational disorders". Social workers provided guidance to these women and put them in contact with the Mental Health Service, an AA group and the Department for Women, respectively. None of the $23(0 / 23)$ children was considered "normal" (a doubtful case was referred to secondary care, but there he was diagnosed with "overall developmental delay"). Five (5/23) children had two or more disorders.

Children with "overall developmental delay" who were not initially attending a CDC, a KG, a N or the workshops on upbringing, physical activity and/or reading provided by the FYP and their mothers (19) were referred to one of these, depending on the institution's availability and/or their parents schedule, and received recommendations and/or indications on specific activities adapted to the intervention's goal, children's age, etc. (CDC: 3; KG: 2; N: 4; FYP: 10).

\section{Follow-up}

Follow-up of some of these cases was performed by the consultant physicians, either partially (hemiparesis) or fully (specific hearing impairment [SHI], SLI); however, most children were studied in different settings (PHCC, home, nursery, school, stimulation units) by any of the three primary care providers, always considering the opinions of the rest of the team members involved, teachers and FYP facilitators, primary caregivers and consultant physicians, who actively collaborated through telephone contacts aimed at clarifying doubts or exchanging referral criteria. Several observations were conducted in a "natural setting" because the PRUNAPE was administered at the same facilities where many of the children involved in this investigation were referred to. The psychologist was mainly responsible for the follow-up and treatment of children with "relational disorders", while the speech therapist was in charge of those with "language developmental delay". The pediatrician, together with these two providers, was responsible for observing children with "overall developmental delay". The child with hemiparesis was also accompanied and assisted by the physical therapist at the PHCC.

Quarterly meetings conducted with personnel from the PHCC and from each school or the FYP, which had been scheduled in advance, were also used to exchange information on participating children and prepare follow-up reports during the investigation.

Once, the teacher of the three-year-old kindergarten classroom asked about a child with communicational problems with his peers and teachers. Since he had not been assessed yet, it was 
decided to administer the screening test to him in advance, and he failed it. During the visit to the pediatrician, he was administered the M-Chat, which he also failed. He was referred to the pediatric psychiatrist with a possible diagnosis of social communication disorder (autism spectrum disorder ASD). The consultant physician confirmed the suspected ASD diagnosis (she performed a BAEPs test first) and put the family in contact with a non-governmental organization (NGO) that provides multimodal and comprehensive care in relation to this condition (Association of Parents of Autistic Children [Asociación Argentina de Padres de Autistas], APADEA). A girl classified as having "relational disorders", numerous tantrums and who had not improved with psychological therapy, and another girl diagnosed with "overall developmental delay" who seemed "clumsier than expected" for her age, were referred to secondary care suspected of having pervasive developmental disorder (PDD) and developmental coordination disorder (DCD), respectively, few months after starting follow-up. In both cases, consultant physicians disregarded these assumptions. The first girl continued receiving psychological therapy; the second girl started physiotherapy sessions and physical activity workshops at the FYP.

During this stage, no other referrals were made in addition to those mentioned above; however, when changes in their course were verified, some of the previous indications were modified.

Follow-up, defined as the period during which each child continued to be supervised between the three initial visits and the end of the study, varied (children who completed the PRUNAPE at the beginning of the study and promptly completed initial visits were observed for a longer period than those who completed these at a later moment). The frequency of follow-up varied for the same and other reasons (e.g., some children attended FYP workshops inconsistently, while other children who attended CDCs and KGs showed a more constant rate of attendance, therefore, observation opportunities differed). Given the characteristics of individual records and problems with verifications, it was not possible to establish the mean and median values of these outcome measures. Notwithstanding this, it could be said that most follow-ups lasted between three and four months, widely ranging from one to nine months.

\section{Re-assessment}

Due to time constraints, it was decided to re-assess children who received no diagnosis at secondary care settings as long as six or more months had elapsed since their initial assessment. A module made up of the following was defined as re-assessment: 1. a new instance of administration of the PRUNAPE; and 2. a scheduled meeting between primary caregivers (always mothers) and their child with the three primary care providers concurrently.

Five children met the criteria for re-assessment. One had dropped out of the follow-up and did not attend ("language developmental delay"; intervention: speech therapy + FYP); two failed the test but did not complete the module ("overall developmental delay"; intervention: FYP, and "relational disorders"; intervention: psychological therapy + FYP); and two completed the module: one failed the test ("overall developmental delay"; intervention: KG) and the other passed the test ("overall developmental delay"; intervention: $C D C$ ). The two children who failed the test but did not complete the module were referred to secondary care to establish their diagnosis and, eventually, new therapeutic goals. They completed some visits at secondary care, but the diagnostic impression remained the same. The parents of the child who failed the test and completed the re-assessment were offered new interventions (KG + speech therapy) at the primary care level because these were deemed the most convenient measures.

\section{Process results}

Overall, 78.8\% (26/33) of children who failed the PRUNAPE were examined. Of these, $69.7 \%(23 / 33)$ completed the initial assessment in the primary care setting. Out of those who completed the assessment, $30.4 \%(7 / 23)$ were referred to secondary care for diagnosis. Fifty percent $(2 / 4)$ of children who underwent a re-assessment were also referred to secondary care to test the initial diagnostic impression. That is to say, 39.1\% (9/23) of children in the set made up of assessed and re-assessed participants were referred to secondary care. One hundred percent (9/9) of children referred to this instance of care attended their visits; $88.9 \%$ (8/9) completed all tests requested by consultant physicians. Forty percent $(2 / 5)$ completed the re-assessment.

Participants were considered dropouts if they did not complete the three visits in the initial stage or the secondary care diagnostic round or if they interrupted the study during follow-up. This was verified 
in 11 cases (seven families decided to miss the initial assessment, three children did not complete it, and another child dropped out of the FYP workshops shortly after starting them). The dropout rate was $33.3 \%(11 / 33)$.

\section{REFERENCES}

1. Lejarraga H. La detección oportuna de problemas del desarrollo. La Prueba Nacional de Pesquisa (PRUNAPE). In: Boggiano E, Breitman F, Andrade M, coords. Comité Nacional de Pediatría General Ambulatoria. SAP. Manual para la Supervisión de la Salud de niños, niñas y adolescentes. Buenos Aires: FUNDASAP; 2010.Págs.447-50.

2. Ripoli M. Dificultades y alternativas para la vigilancia y promoción del desarrollo en el primer nivel de atención). In: Lejarraga H, ed. Desarrollo del niño en contexto. 1.a ed. Buenos Aires: Paidós; 2004;11:435-46. 


\section{Annex 2. \\ List of outcome measures assessed in this study, grouped by level of risk assessment* and definitions}

\begin{tabular}{|c|c|c|}
\hline Level & Outcome measure & Definition \\
\hline 0 & Proportion of boys & Number of boys per 100 children. \\
\hline \multirow[t]{5}{*}{1} & Socioeconomic level & $\begin{array}{l}\text { Score obtained at the SEL-CESNI scale established based } \\
\text { on an interview with one or both parents at home. }\end{array}$ \\
\hline & Maternal education & Years completed in the formal educational system. \\
\hline & Educational environment & $\begin{array}{l}\text { Average number of years completed in the formal educational } \\
\text { system by both biological parents. }\end{array}$ \\
\hline & $\begin{array}{l}\text { Head of household with } \\
\text { an unstable job }\end{array}$ & $\begin{array}{l}\text { Man or woman (if the couple is separated) at present without } \\
\text { a job or receiving social assistance or working odd jobs. }\end{array}$ \\
\hline & $\begin{array}{l}\text { Head of household with } \\
\text { a qualified job }\end{array}$ & $\begin{array}{l}\text { Man or woman (if the couple is separated) } \\
\text { certified to do their job. }\end{array}$ \\
\hline \multirow[t]{6}{*}{2} & $\begin{array}{l}\text { Child's age } \\
\text { Family of Quechua } \\
\text { ethnicity }\end{array}$ & $\begin{array}{l}\text { Decimal age at the time of taking the first PRUNAPE. } \\
\text { Family where the maternal role is played by a Quechua } \\
\text { woman born in Bolivia or another country (e.g.: Argentina), } \\
\text { as long as her own mother was also in the same ethnic group. }\end{array}$ \\
\hline & Separated parents & $\begin{array}{l}\text { The child's biological parents, previously married or living } \\
\text { together, but who were not living together at the time of } \\
\text { the interview. }\end{array}$ \\
\hline & Maternal age & Age at the time of giving birth. \\
\hline & Number of children & $\begin{array}{l}\text { Total number of biological or adopted (legally or otherwise) } \\
\text { children at the time of the interview. }\end{array}$ \\
\hline & Pathological pregnancy & $\begin{array}{l}\text { If IUGR, diabetes, toxemia or mental disorder were diagnosed } \\
\text { during a previous pregnancy. } \\
\text { The option "others" is for other significant harmful effects. }\end{array}$ \\
\hline & Family risk ${ }^{\#}$ & $\begin{array}{l}\text { Drug abuse, family violence or chronic disease in any of the } \\
\text { parents. }\end{array}$ \\
\hline \multirow[t]{2}{*}{3} & Birth weight & Birth weight in grams, recorded in the child's health card. \\
\hline & Insufficient birth weight & $\begin{array}{l}\text { Birth weight between } 2500 \text { grams and } 2999 \text { grams, recorded } \\
\text { in the child's health card. }\end{array}$ \\
\hline \multirow[t]{6}{*}{4} & Full-time housewife & $\begin{array}{l}\text { Biological mother with no formal or informal job inside } \\
\text { or outside the home. }\end{array}$ \\
\hline & $\begin{array}{l}\text { Mother who works a lot } \\
\text { outside the home }\end{array}$ & $\begin{array}{l}\text { Biological mother who works five hours a day on five } \\
\text { or more days a week, either a formal or informal job. }\end{array}$ \\
\hline & Only child & $\begin{array}{l}\text { A child with no biological or adopted (legally or otherwise) } \\
\text { siblings at the time of the interview. }\end{array}$ \\
\hline & First child & First born child. \\
\hline & Breastfeeding ${ }^{\#}$ & Exclusive maternal breastfeeding for more than three months. \\
\hline & Informal childcare & $\begin{array}{l}\text { Informal institutions (maternal homes) and/or, frequently, } \\
\text { non-institutional settings (family members or others), } \\
\text { in addition to parents. }\end{array}$ \\
\hline
\end{tabular}


Formal institutions (CDC or kindergarten), in addition to parents.

Health checkups Number of health checkups performed by physicians, recorded in the child's medical record or health card in the year prior to the interview.

$5 \quad$ Z scores for H-A

Difference between the child's height-for-age and the median value for age and sex.

W-H above $+2 \mathrm{SD}$ $\mathrm{W}-\mathrm{H}$ value above $+2 \mathrm{SD}$ (obesity).

Wasting ${ }^{\circ} \#$ $\mathrm{W}-\mathrm{H}$ value below $2 \mathrm{SD}$.

Significant disease

A common disease that does not affect development but that required hospitalization, with length of stay shorter than 30 days, either resolved or controlled, and that does not alter activities of daily living.

SEL: socioeconomic level; CESNI: Child Nutrition Study Center (Centro de Estudios Sobre Nutrición Infantil); H-A: height-for-age; W-H: weight-for-height; SD: standard deviation; CDC: child development center; PRUNAPE: National Developmental Screening Test; IUGR: intrauterine growth restriction.

*Levels indicate the position of outcome measures in a hierarchical model for risk assessment.23 Level 0: sex; level 1: related to social status; level 2: related to reproductive and socioenvironmental characteristics; level 3: related to birth; level 4: related to care provided to the child; level 5: related to malnutrition and other overt health problems.

$\sim$ Method for measuring poverty, based on the method developed by the National Statistics and Censuses Institute of Argentina (Instituto Nacional de Estadística y Censos, INDEC),a used for the National Survey on Nutrition and Health (ENNyS, 2004-2005) and other studies conducted in Argentina (Tierra del Fuego Project).13 It is made up of two indicators that assess economic status (house $-30 \%-$, slums -10\%-) and two that assess social status (formal education -30\%-, occupational category $-30 \%-)$.

a Maps of poverty in Argentina. Work Document No. 4. Buenos Aires, Committee to study poverty in Argentina (Comité para el estudio de la Pobreza en la Argentina, CEPA), 1994.

\# Pre-selected outcome measures that were then omitted (in italics) for the following reasons: cases of family risk detected during diagnosis and follow-up that had not been identified during the home interviews conducted by social workers in order to identify possible RFs; the questionnaire on breastfeeding did not include definitions of terms and, as a result, was incorrectly completed by operators; no wasting case was observed among the 60 studied minors.

${ }^{\circ}$ As per the WHO references (2006). 


\section{Annex 3. \\ Population and sample distribution by region}

\begin{tabular}{lcccc} 
& \multicolumn{2}{c}{ Population } & \multicolumn{2}{c}{ Sample* $^{*}$} \\
& $\mathbf{n}$ & $\%$ & 39 & 65,0 \\
\hline Region 1 & 103 & 66,0 & 21 & 35,0 \\
Region 2 & 53 & 34,0 & 60 & 100,0 \\
Total & 156 & 100,0 & & n \\
\hline
\end{tabular}

* Differences in the percentage of representation in each region between population and sample are not significant (Z-test for proportions, $p=0.44$ ). 